\title{
UM EPISÓDIO DE PRODUÇÃO DE SUBJETIVIDADE NO BRASIL DE 1930: MALANDRAGEM E ESTADO NOVO
}

José Novaes*

\begin{abstract}
RESUMO. Este trabalho aborda um aspecto do tema, extremamente vasto e complexo, da malandragem no Brasil, em um de seus momentos mais esclarecedores para a análise: o período getulista de governo, especialmente o Estado Novo (1937 - 1945). Mostra o embate entre as concepções e as práticas da malandragem e aquelas formadas pelos acontecimento históricos, políticos e sociais da década de 30, quando o governo Vargas sentiu a necessidade de criar novas mentalidades, subjetividades e uma nova cultura, que impulsionassem o seu projeto de construção nacional através de exemplos de obras da música popular brasileira. O samba, especificamente, que adotou desde o seu surgimento, com rápida aceitação por amplas camadas sociais, uma "dicção malandra", é um filão inesgotável para mostrar como se deu este conflito, que caminhos seguiu, e seu desfecho - que é apenas o de uma fase, já que malandros e malandragem permanecem como figuras de nossa realidade social.
\end{abstract}

Palavras-chave: malandragem, Estado-Novo, música popular brasileira.

\section{AN EPISODE OF SUBJECTIVITY PRODUCTION IN BRAZIL IN 1930: ROGUERY AND THE NEW STATE}

\begin{abstract}
This work approaches an aspect of the extremely vast and complex subject of roguery in Brazil, in one of its more revealing moments for the analysis: the Getulista government period, more specifically the New State (1937 - 1945). The clash between the conceptions and practices of roguery and those, formed by the historical, political and social events of the thirties with the need of Vargas government for creating a new mentality, subjectivity, and a new culture, that impelled its project of national construction, is shown with examples of works of the Brazilian popular music. Specifically the samba, that adopted since its appearance, with fast acceptance by wide social classes a "roguish diction", it is an inexhaustible source to show how this conflict was started, which roads it proceeded, and its outcome - which is just a phase, since scoundrels and roguery remain as part of our social reality.
\end{abstract}

Key words: roguery, New State, Brazilian popular music.

\section{INTRODUÇÃO}

Os meios de comunicação de massa tiveram sempre, no século $\mathrm{XX}$, um papel importante na produção de subjetividades. Nas décadas de 20,30 e 40, nos EUA, a imprensa, o rádio e o cinema formaram gostos, preferências e aversões, gerando costumes e provocando o consumo, criando hábitos e produzindo modos de perceber, sentir, pensar e agir, ou seja, subjetividades ${ }^{1}$. Em 1944, Adorno e Horkheimer (1986) analisavam este fenômeno em um capítulo - "A indústria Cultural" - de sua obra "Dialética do esclarecimento".

Neste trabalho, procuro apresentar brevemente um momento, na história de nosso país, em que este processo de produção de subjetividades, por meio

\footnotetext{
Psicólogo, Diretor do Instituto de Ciências Humanas e Filosofia, ICHF/UFF, Doutor pela Escola de Comunicação da UFRJ, professor Adjunto do Departamento de Psicologia da Universidade Federal Fluminense (UFF), Niterói, Rio de Janeiro.

Endereço para correspondência: Rua Maranhão, 206 - Méier - Rio de Janeiro - RJ. CEP - 20720-230. Telefax: (21) $3899-0995$.

1 O termo "subjetividade"é usado, aqui, na acepção que lhe confere F. Guattari, em substituição aos termos tradicionalmente usados nas disciplinas humanas, como os de "sujeito", "eu”, "personalidade", "indivíduo". Para Guattari, estas concepções essencializam e naturalizam algo que é produzido "de fora", nos equipamentos coletivos, sociais, e que não surge "de dentro", pelo desenvolvimento de tendências imanentes, já dadas "a priori". Ver: Guattari, F. \& Rolnik, S. (1986). Subjetividade e História. Em Micropolítica - Cartografias do desejo. Petrópolis: Vozes.
} 
principalmente da mídia e usando produtos culturais no caso, a música popular brasileira - ocorreu de modo intenso.

\section{MÚSICA POPULAR BRASILEIRA: O SAMBA}

A música popular brasileira sempre foi um poderoso aparato de produção de subjetividades. Várias características o explicam: entre elas, sua ligação com as camadas populares de onde surgiu, expressando seus problemas, suas necessidades, seus anseios; e também por ser uma representação nãopassiva da realidade destas camadas. Assim como expressava o cotidiano da vida social brasileira, com tipos, costumes, subjetividades, especialmente destas camadas populares, ela interferia nesta mesma realidade, acentuando certos traços e certas características, sedimentando os modos de perceber, pensar, sentir e agir, e mudando outros, em movimentos e alternâncias que acompanhavam as transformações desta realidade, às vezes mesmo antecipando-se a elas. Exemplo: o Tropicalismo, Caetano Veloso e Gilberto Gil à frente, em 1967/1968, reunindo e solidificando aspectos difusos, tendências artísticas diversas, expressas aqui e ali, no cinema de Glauber Rocha, nas artes plásticas de Hélio Oiticica e outros. Pedro Alexandre Sanches (2000) apresenta estas idéias em sua obra recente: Tropicalismo: decadência bonita do samba.

Depois, sua riqueza e variedade a tornaram comparável ao acervo da produção popular de qualquer outro país, neste campo. Cito alguns exemplos: primeiro, a modinha, no final do século XVIII, o primeiro gênero reconhecido. Depois, o choro - inicialmente não um gênero, mas um modo de tocar, pelos conjuntos que reuniam flauta, violão e cavaquinho, as músicas populares da época. E recentemente o samba, no início do século $\mathrm{XX}$, e os diversos gêneros regionais que conseguiram difusão nacional, como os nordestinos baião, xaxado, e outros

Veja-se o samba; e não por acaso, mas por ser ele o mais conhecido, estudado, pesquisado, permitindo que a tese seja argumentada. Surgido como gênero distinto e identificável nas duas primeiras décadas de nosso século, o samba tornou-se, vinte anos mais tarde, na década de 1930 portanto, o gênero de música popular brasileira mais difundido, conhecido e aceito em todo o país. Como cantava Noel Rosa, no início da década de 30: "O samba / A prontidão / E outras bossas / São nossas coisas / São coisas nossas"”2.

\footnotetext{
${ }^{2}$ Noel Rosa: Coisas nossas - 1932
}

O samba surgiu das comunidades negras que se estabeleciam no Rio de Janeiro, após a abolição e no início do século XX. Muitos vinham da Bahia, e nesses grupos baianos estavam os mais 'politizados', os mais conscientes das necessidades de seu povo: manterem-se unidos, congregados, solidários, resgatar e fazer sobreviver sua cultura, seus costumes, através da religião, das festas e rituais, e da música. O samba era inicialmente, portanto, para essas comunidades negras do Rio, um elemento poderoso que servia ao ritual de congraçamento e união de seu povo, e sua criação era coletiva. Este, talvez, o aspecto mais importante para se entender a celeuma em torno do que foi considerado o primeiro samba gravado, o "Pelo telefone", de Donga - Ernesto Joaquim Maria dos Santos - e Mauro de Almeida. (Adverte-nos um grande pesquisador da música popular brasileira, José Ramos Tinhorão: "Samba com ritmo de samba", embora ainda muito amaxixado). O escândalo decorria da inserção, no circuito comercial, de uma criação coletiva com características quase rituais, religiosas, como era usado o samba pelas comunidades negras do Rio de Janeiro ${ }^{3}$

Já nas décadas de 1910 e 1920 com Sinhô - José Barbosa da Silva - , Ismael Silva, e na década de 1930 com Noel Rosa, Geraldo Pereira, Wilson Batista, o samba tornou-se o mais importante gênero da música popular brasileira. Contribuíram para isso seu uso no carnaval, mas, principalmente, sua difusão pelo rádio, que na década de 1930 alcançava todo o território nacional, tornando-se o mais importante meio de comunicação. A partir principalmente de 1937 e até o final do Estado Novo, em 1945, houve um motivo complementar e poderoso para isso: a cooptação do samba pelo governo getulista para impor o seu projeto de nação.

\section{SAMBA E MALANDRAGEM NOS TEMPOS DE GETÚLIO}

Os ideólogos e propagandistas do Estado Novo sabiam o que faziam. Sua escolha do samba como canal para aproximação e conquista das camadas populares não foi por acaso. O samba, em cerca de 20 anos, já estava profundamente entranhado no gosto popular, por falar do povo, de suas agruras, de suas dificuldades, suas expectativas e seus sonhos. A figura que imperava, aí, era a do malandro, que está ligada intimamente ao surgimento e desenvolvimento do

Roberto Moura (1987) conta com detalhes o episódio em sua obra: Tia Ciata e a Pequena África no Rio de Janeiro. Rio de Janeiro: Funarte. 
samba em suas décadas iniciais. Gilberto Vasconcellos e Matinas Suzuki Jr. traçam, com passos concisos e certeiros, a história deste conúbio, em seu artigo: "A malandragem e a formação da música popular brasileira", dizendo:

"Em sua fase heróica - no período de formação a música popular brasileira encontrava seu circuito à margem do trabalho que, no dizer de Caio Prado Jr., 'se torna ocupação pejorativa e desabonadora'. Fora da escravidão, o músico escapava às fronteiras do trabalho braçal... O que se pretende chamar atenção é para o próprio fenômeno da MPB já nascer sob o signo da malandragem, episódio que a marcará profundamente até os nossos dias. $\mathrm{O}$ fato dos primeiros compositores da nossa música popular perambularem pela malandragem não é ocasional: eles revelam o parentesco original que existe entre a música popular e a malandragem no Brasil".

E foi justamente contra essa louvação do malandro que o Estado Novo teve que lutar, para substituir essa imagem pela do trabalhador, imprescindível ao seu projeto de construção da nação brasileira. Enquanto em 1931 Ismael Silva dizia "Se eu precisar algum dia / De ir pro batente / Não sei o que será / Pois vivo na malandragem / E vida melhor não há... / O trabalho não é bom / Ninguém pode duvidar / Oi, trabalhar só obrigado / Por gosto ninguém vai lá"4, em 1940 W. Batista, malandro e sambista, 'regenerava-se' respondendo: "Quem trabalha é que tem razão / Eu digo e não tenho medo de errar... / O bonde de São Januário / Leva mais um operário / Sou eu que vou trabalhar,"5.

Pode-se, é claro, interpretar isto como tática de sobrevivência pessoal de Wilson Batista, que como bom malandro sabia que não podia continuar na mesma rota de poucos anos atrás, quando dizia no samba que iniciou sua famosa polêmica com Noel Rosa: "Meu chapéu de lado / Tamanco arrastado / Lenço no pescoço / Navalha no bolso / Eu passo gingando / Provoco e desafio / Eu tenho orgulho / Em ser tão vadio". E tática de sobrevivência também do samba como criação popular, e que se dobrava a

4 "O que será de mim", de Ismael Silva, Nilton Bastos e Francisco Alves - 1931

5 "O bonde de São Januário", de Wilson Batista, Ataulfo Alves - 1940. Este samba fez enorme sucesso no carnaval de 1941, e as histórias em torno dele - sua composição, os "motivos"que teriam levado Wilson Batista a compô-lo, são contadas por Moby (obra citada), e no verbete correspondente ao samba em: A canção no tempo - 85 anos de músicas brasileiras. Vol. 1 (1901 - 1957), de Jairo Severiano e Zuza Homem de Melo - Rio de Janeiro, Editora 34, 1997. novos ventos que sopravam, mas espertamente poderia renascer com seu teor de crítica social, quando Almeidinha, mal terminado o Estado Novo, lançava seu samba de carnaval de 1946: "Trabalhar, eu não, eu não ... / Trabalho, não tenho nada / De fome não morro não / Trabalhar, eu não, eu não"6 .

A malandragem, nas primeiras décadas do século XX no Brasil, deve ser entendida como rejeição ao trabalho e como modo de sobrevivência. Numa sociedade profundamente injusta, em que centenas de milhares de ex-escravos foram jogados - e o termo é esse mesmo, para acentuar o aspecto violento e cruel do fato - ao mercado de trabalho, sem ter, a imensa maioria, capacidade ou formação para competir com os trabalhadores brancos brasileiros e os imigrantes que aqui chegavam em grande número, a malandragem era uma das estratégias que poderia dar garantias mínimas de vida. Não se poderia esperar que o trabalho fosse considerado, por grandes parcelas da população, uma atividade digna. Não tinha valor moral, não compensava materialmente, e só a mínima parte dos que o procuravam como ocupação conseguiam alcançá-lo.

Nada de espantar, portanto, que surgisse e se firmasse a figura do malandro, esgueirando-se entre as frestas do sistema instituído. Já no século XIX as instituições do favor e do clientelismo eram comuns; no século XX, o malandro apenas continuaria esta tradição ${ }^{7}$. Pequenos - e às vezes grandes - golpes e expedientes, o jogo, o rufianismo, a estia - a venda de 'proteção' a comerciantes - eram seus meios de vida. A rejeição ao trabalho era um dos princípios básicos: os 'otários' eram aqueles que se entregavam à escravidão dos horários impostos, o tratamento humilhante por parte dos chefes, as condições miseráveis, insalubres, injustas e desumanas em que labutava a imensa maioria dos trabalhadores.

"Malandro" e "malandragem" são termos escorregadios, carregados de complexidade, mostrando a enorme diversificação que suas realidades tiveram, ao longo do tempo, na vida social. Um lingüista diria: são termos polissêmicos, de significado mutável na história. Vasconcellos e Suzuki trazem à baila, em seu artigo citado acima, a figura do pícaro, no romance e na literatura espanhola do século XVII;

\footnotetext{
6 "Trabalhar, eu não", de Almeidinha (Aníbal Alves de Almeida) - 1946.

7 O ensaio clássico de Antonio Candido, "Dialética da Malandragem", analisa a figura do malandro na década de 1850, através do romance de Manuel Antonio de Almeida: Memória de um sargento de milícias. Ver: Candido, A. (1993). Dialética da Malandragem. Em O Discurso e a Cidade. São Paulo: Duas Cidades.
} 
Antonio Candido, como já referido, anota sua existência no Brasil de 1850.

Gilberto Vasconcellos, em obra de 1977, "Música popular: de olho na fresta", afirma:

... malandragem (é) tema que atravessa a MPB de ponta a ponta. Compositor popular neste país é malandro. Aviso importante: ele não precisa, entretanto, viver necessariamente de trambique, perambular bebunado pelas sinucas da cidade, nem mesmo nascer no morro... Sua origem de classe também conta ponto. Certo, Sinhô e Ismael Silva vêm das camadas mais baixas da população carioca [Nota minha, J.N.: Ismael Silva, em verdade, é niteroiense, não carioca; mas teve origem em classe popular]. Mas Noel é de classe média... Alberto Ribeiro, médico. Por isso mesmo, refiro-me à malandragem enquanto metáfora. $\mathrm{O}$ que não significa dizer que ela não tenha origem histórico-social.

Adiante, o mesmo autor continua a argumentação, dizendo do "significado polivalente" da malandragem: "No percurso da MPB, cada compositor empresta-lhe, volta e meia, um significado diferente... Parafraseando o vate português: muda-se o tempo, muda-se o vadio... A barra, hoje, é diferente; conseqüentemente, outra a manha".

E, para voltar ao tema que sugeriu estas notas, o do casamento indissolúvel entre o nascimento do samba e suas primeiras décadas de consolidação, e a malandragem: Vasconcellos refere-se ao final da década de 1920 e ao decorrer da década de 1930.

Fato curioso e sintomático: os críticos da imprensa da época não viam com bons olhos o rumo que seguiu a música popular. Era preciso acabar com essa mania de elogiar a orgia, a gandaia, a fuzarca - pontificava a crítica musical bem comportada... A tendência, ainda hoje, é considerá-la sob a angulação anedótica; como se ela não tivesse nada a ver com a nossa vida social... Enquanto a maioria da população é obrigada a ingressar na produção e viver de um trabalho mais ou menos regular, submetendo-se às exigências da labuta em conformidade com o código ideológico dominante, o malandro sublinha nosso cancioneiro popular - parece ter um destino social mais brando, dando aqui e ali um jeitinho no aperto, através de sua irresistível picardia e de sua visagem sedutora.

A partir da ampla aceitação popular do samba, e tendo em vista suas raízes nas camadas populares, nas décadas de 1920 e 1930, um dos "jeitinhos" encontrados pelo malandro foi ser compositor popular
- de samba, especialmente. A maioria dos grandes compositores deste período, na música popular, era composta de "malandros": Sinhô, Ismael Silva e a turma do Estácio - Bide (Alcebíades Barcelos), Nilton Bastos, etc. - Wilson Batista, Geraldo Pereira; ou era fascinado pela figura e aceitava sua ideologia e seu modo de perceber a realidade, como era o caso do Noel Rosa.

O governo getulista, tentando impor e implementar seu projeto de construção do país através do trabalho, teve, portanto, que lutar contra esse atraente modo de vida: a malandragem. E o fez com denodo, de modo sistemático, mobilizando nesta tarefa todos os seus "intelectuais orgânicos", e usando todos os meios a seu dispor. Dois deles, de inegável eficácia: o samba, extremamente popular, e que até então cantava loas ao malandro, e o rádio, com seu poder enorme de difusão, que alcançava todo o país. O DIP - Departamento de Imprensa e Propaganda - ocupouse em cooptar os sambistas, compositores, críticos, colunistas; "organizou" e regulamentou o carnaval, instituindo as regras de desfile das escolas de samba, os prêmios às melhores músicas, os concursos etc... Ao lado disso, o aspecto mais repressivo era escondido, a censura existia mas agia nas sombras, e tentava, por sedução e convencimento, o consenso ${ }^{8}$. Surge o samba-exaltação, falando das maravilhas do país, "essas fontes murmurantes onde eu mato a minha sede", do "Brasil lindo e trigueiro", como dizia Ary Barroso em "Aquarela do Brasil"(1939). O sambaexaltação cantava a natureza do Brasil; os problemas sociais eram jogados para baixo do tapete, para não incomodar e turvar o retrato límpido e glorioso de "praias tão claras" e "flores tão raras", de "nossas fontes, nossas ilhas e matas, nossos montes, nossas lindas cascatas" - "Deus foi quem criou", afirmava outro samba, do mesmo Ary Barroso ("Rio de Janeiro - Isto é meu Brasil", de 1951. Aliás,

Isto é analisado por Alberto Ribeiro da Silva (Alberto Moby), em sua obra, produto de dissertação de mestrado na Pós-Graduação de História na Universidade Federal Fluminense, Sinal Fechado - A música popular brasileira sob censura. Rio de Janeiro, Obra Aberta, 1994. Moby estuda dois períodos ditatoriais: o getulista, especialmente de 1937 a 1945 - o Estado Novo - e a ditadura militar, 1967 a 1985. Entre outras conclusões, argumenta que o Estado Novo getulista procurava o consenso, e cooptava os sambistas, críticos, cronistas,etc, sendo a censura e a repressão mais violentas pouco - ou nada - utilizadas, enquanto a ditadura militar reprimia aberta e violentamente - inclusive fisicamente - com ameaças, prisões, forçando ao exílio, etc. Também Cláudia Matos e Ruben George Oliven, cujas obras são citadas nas Referências bibliográficas, abordam o tema. 
"coincidentemente", Getúlio Vargas voltara à Presidência da República).

\section{À GUISA DE CONCLUSÃO: SAMBA E RESISTÊNCIA}

Tentei mostrar, brevemente, um momento na história de nosso país em que, por força de injunções político-sociais e utilizando formas culturais, ocorre uma certa produção de subjetividade. A "subjetividade malandra", que conseguira larga divulgação popular por, entre outros motivos, estar intimamente ligada à gênese de uma das maiores criações culturais das classes subalternas, o samba, vê-se atacada e desqualificada em favor de uma outra, eficazmente construída à época: a do trabalhador. Nesta se concentram as qualidades agora exaltadas, e necessárias para a construção da nação: a honestidade, o esforço, a integridade; enfim, tudo aquilo que se opunha à malandragem. $\mathrm{O}$ malandro é apresentado de modo negativo, apenas como tendo 'boa vida', flanando alegre e despreocupado pela Lapa, o bairro da malandragem. Na verdade, o malandro nunca teve boa-vida, nunca foi aceito pelos poderosos, sempre foi perseguido, e sempre que possível era mostrado apenas num dos seus tipos: o marginal, perigoso, violento, assassino, o que justificava a repressão que sobre ele se exercia ${ }^{9}$.

Os meios de comunicação da época - décadas de 30, 40, 50 - são mobilizados para esta batalha de produção de novas subjetividades, que se adequassem aos ditames das forças políticas hegemônicas da ocasião. A imprensa e o rádio se conjugam aos esforços dos governos para elevar o trabalho e o trabalhador a um posto de honra, por contribuir para a construção da nação, do novo país emergente. Neste processo, muito contribuiu a formação da indústria cultural na área da música popular.

A transformação da cultura em mercadoria, tendência central sistemática da indústria cultural, com a padronização e o rebaixamento de seus produtos,

9 Na verdade, enquanto categoria sociológica, o malandro é algo muito controvertido, como já visto. Sua caracterização como marginal, freqüentemente adotada, pode ser interpretada juridicamente, pelo viés policial, o que permitiria sua identificação com o delinqüente, o criminoso, o assassino mesmo. Alguns de seus retratos, feitos por admiradores ou por malandros históricos, famosos mesmo, como Wilson Batista, no samba citado, "Lenço no pescoço", revelam como era comum e fácil, mesmo no meio da malandragem, aceitar estas conotações pejorativas, negativas: Wilson pintava o malandro como o vadio, valente, provocador, de "navalha no bolso". criando hábitos de consumo e dominando os gostos pela força do dinheiro e pelas imposições do mercado, serviu para o abastardamento de uma das criações mais genuínas da música popular brasileira. Não é só a aura da obra de arte que se perde na época de sua reprodutibilidade técnica, como afirmava o pensador alemão Walter Benjamim. Perde-se também a memória, no caso do samba, de suas raízes nas camadas mais subalternas da sociedade do Rio de Janeiro do início do século, as comunidades negras e de trabalhadores, pequenos comerciários, semiempregados, ocupantes da 'economia informal', enfim, a camada 'mais baixa' do povo. E perde-se também a característica do samba como retrato dessa situação, do cotidiano dessa gente, de suas pequenas alegrias e grandes dores, contentamentos ínfimos e extremas preocupações, mas de qualquer modo uma criação sua, que falava de realidades na qual esta gente podia se ver e com a qual podia se identificar. Hoje o samba massificado, pasteurizado, pobre em letras e ritmos, em melodias lamentáveis e repetitivas, domina as rádios, tevês e ajuda a produzir subjetividades conformadas, apáticas, inconscientes de sua situação social, ignorantes de seus direitos mínimos, pois somente as mazelas e desventuras, ou as pequenas alegrias de um sentimentalismo barato lhes são oferecidas. Essa é a subjetividade hegemônica hoje produzida e difundida nos meios de comunicação de massa. Há resistências, é claro: Paulinho da Viola, João Nogueira, Fundo de Quintal, Zeca Pagodinho, Dona Ivone Lara, Monarco, Nelson Sargento, Nei Lopes, Wilson Moreira, Monarco e a Velha Guarda da Portela, Walter Alfaiate, e que me perdoem os não citados, que espero continuem lutando contra a maré montante do 'sambrega' que nos assola.

\section{REFERÊNCIAS BIBLIOGRÁFICAS:}

Adorno, T. W., \& Horkheimer, M. (1986). Dialética do Esclarecimento (A. G. de Almeida, Trad.). Rio de Janeiro: Jorge Zahar. (Originalmente publicado em 1947).

Benjamin, W. (1985). Magia e Técnica - Arte e Política (Obras escolhidas, vol. 1). (S. P. Rouanet, Trad.). São Paulo: Brasiliense. (Originalmente publicado em 1955).

Candido, A. (1993). Dialética da Malandragem. Em $O$ Discurso e a Cidade. (pp. 19-54). São Paulo: Duas Cidades.

Guattari, F., \& Rolnick, S. (1986). Micropolítica Cartografias do Desejo. Petrópolis: Vozes.

Matos, C. (1982). Acertei no milhar - Samba e malandragem no tempo de Getúlio. Rio de Janeiro: Paz e Terra. 
Moura, R. (1987). Tia Ciata e a pequena África no Rio de Janeiro. Rio de Janeiro: Funarte.

Novaes, J. (1999). Luto e melancolia na Música Popular Brasileira: Nelson Cavaquinho. Tese de doutorado. Universidade Federal do Rio de Janeiro, Rio de Janeiro.

Oliven, R. G. (1983). Violência e Cultura no Brasil. Petrópolis: Vozes.

Sanches, P. A. (2000). Tropicalismo - Decadência bonita do samba. São Paulo: Boitempo.

Severiano, J., \& Homem de Melo, Z. (1977). A canção no tempo - 85 anos de músicas brasileiras. 1 e 2 . Rio de Janeiro: Editora 34.

Silva, A. R. da (Moby) (1994). Sinal fechado - A música popular brasileira sob censura - Rio de Janeiro: Obra Aberta.
Tinhorão, J. R. (1991). Pesquisa histórica da música popular - Da modinha à lambada. São Paulo: Art Editora.

Vasconcellos, G. (1977). Música popular: de olho na fresta. Rio de Janeiro: Graal.

Vasconcellos, G., \& Suzuki Jr., M. (1995). A malandragem e a formação da música popular brasileira. Em B. Fausto (dir.). História Geral da Civilização Brasileira. (pp. 501523). Rio de Janeiro/São Paulo: Bertrand-Brasil.

Recebido em 08/12/2000 Revisado em 02/04/2001 Aceito em 30/05/2001 